\title{
ADOECIMENTO MENTAL NA EDUCAÇÃO PROFISSIONAL E TECNOLÓGICA: O QUE PENSAM OS ESTUDANTES CONCLUINTES DE CURSOS TÉCNICO INTEGRADOS
}

\author{
Fabiane do Amaral Pacheco*, Sandra Elisabet Bazana Nonenmacher, Adão Caron Cambraia \\ *E-mail: fabidamaral@gmail.com \\ Instituto Federal Farroupilha, Brasil \\ DOI: 10.15628/rbept.2020.9173
}

Artigo submetido em nov/2019 e aceito em dez/2019

\begin{abstract}
RESUMO
Este artigo resulta de uma pesquisa qualitativa que teve como objetivo investigar os possíveis fatores de sofrimento/adoecimento mental relacionados ao contexto escolar de estudantes concluintes de três cursos de Ensino Médio Integrado da Educação Profissional e Tecnológica de um Campus do Instituto Federal Farroupilha. O instrumento utilizado para a coleta dos dados foi o questionário. Para a análise dos dados, a metodologia utilizada foi a Análise de Conteúdo, que permitiu identificar possíveis fatores causadores de prejuízos ao seu bem-estar físico e/ou emocional, entre eles, dificuldades de adaptação à instituição, dificuldades de relacionamento, bullying e pressão por bom desempenho escolar. Além disso, os estudantes identificam a importância dos processos de interação com colegas, professores e servidores como formas de enfrentamento das dificuldades relacionadas ao contexto escolar.
\end{abstract}

Palavras-chave: Educação Profissional. Sofrimento Mental. Interação.

\section{MENTAL ADEQUACY IN PROFESSIONAL AND TECHNOLOGICAL EDUCATION: WHAT THOUGHT STUDENTS INCLUDE INTEGRATED TECHNICAL COURSES}

\begin{abstract}
This article is the result of a qualitative research that aimed to investigate the possible factors of suffering / mental illness related to the school context of graduating students of three Integrated High School Vocational and Technological Education in a Campus Federal Institute Farroupilha. The instrument used for data collection was the questionnaire. For the data analysis, the methodology used was the Content Analysis, which allowed identifying possible factors that cause damage to their physical and / or emotional well-being, among them, difficulties in adapting to the institution, relationship difficulties, bullying and pressure. for good school performance. In addition, students identify the importance of interaction processes with peers, teachers and servers as ways of coping with difficulties related to the school context.
\end{abstract}

Keywords: Professional education. Mental suffering. Interaction. 


\section{INTRODUÇÃO}

Garantida constitucionalmente, a educação está entre os direitos sociais contemplados no artigo 6으 da Carta Magna de 1988. Juntamente com a saúde, o trabalho, a previdência e assistência social, o lazer, a segurança e a proteção à maternidade e à infância, a educação desempenha papel fundamental para o bem-estar social da população, sendo determinante para a superação das mais diferentes formas de vulnerabilidade social.

Estabelecida legalmente, a Educação Profissional e Tecnológica (EPT) ocupa importante lugar na estrutura organizacional da educação brasileira, integra-se aos diferentes níveis e modalidades de educação e às dimensões do trabalho, da ciência e da tecnologia.

Estudantes na faixa etária da adolescência ocupam boa parte das vagas da Educação Profissional e Tecnológica, especialmente no Ensino Médio Integrado (EMI). Os discentes que estão na faixa etária da adolescência necessitam de atenção especial, pois esse período de vida é caracterizado por instabilidades e incertezas, que podem desencadear muitos problemas, inclusive referentes à saúde mental. A adolescência é marcada por várias mudanças que passam pelas questões biológicas, neurológicas e psicossociais. Por este motivo, pode ser um período de dificuldades para o adolescente, muitas vezes, caracterizado como turbulento, já que são várias as mudanças (GROLLI; VAGNER; DALBOSCO, 2017).

Dada a fase de vida em que se encontram os estudantes da EPT, a grande carga de estudos dos cursos integrados, as dúvidas quanto à vida profissional - dentre outras questões e tensões - esses discentes merecem ser observados e escutados, pois todas essas condições podem deixá-los vulneráveis. Com isso, podem ter dificuldades em relação ao bem-estar biopsicossocial e, consequentemente, apresentar sinais de adoecimento.

Considerando a representatividade da população adolescente na EPT, a importância do tema saúde mental, e a potencial incidência de casos de adoecimento nestes indivíduos, parece suficiente a motivação para estudar o tema saúde mental e as possíveis relações com o contexto escolar de discentes da EPT.

Dessa forma, neste artigo são apresentados alguns resultados que integraram uma pesquisa desenvolvida no Programa de Pós-Graduação em Educação Profissional e Tecnológica e que teve como objetivo investigar possíveis fatores de sofrimento/adoecimento mental relacionados ao contexto escolar de estudantes concluintes de três cursos de ensino médio integrado da educação profissional e tecnológica de um Campus do Instituto Federal Farroupilha. 


\section{METODOLOGIA}

A fim de atingir os objetivos desta pesquisa foi desenvolvido um estudo de abordagem qualitativa, uma vez que busca sob a perspectiva de captar as subjetividades, particularidades e experiências dos sujeitos, aproximar-se de sua realidade. Flick (2009, p. 24) ao citar a pesquisa qualitativa a respeito de temas como saúde mental diz que "as inter-relações são descritas no contexto concreto do caso e explicadas em relação a este", por isso quanto aos objetivos, a pesquisa caracteriza-se como descritiva, buscando identificar as inter-relações entre saúde/doença e contexto escolar. Para isso, optou-se pela realização de um estudo de caso que, segundo Yin (2015), é uma investigação empírica que permite o estudo de um fenômeno contemporâneo dentro de seu contexto da vida real.

Destarte, a fim de realizar este estudo de caso identificam-se como os sujeitos da pesquisa os estudantes do terceiro ano do ensino médio integrado da educação profissional e tecnológica nos cursos Técnicos em Administração, em Agropecuária e em Manutenção e Suporte em Informática do Instituto Federal Farroupilha - Campus São Vicente do Sul (IFFar - Campus São Vicente do Sul). A população de estudantes do último ano dos três cursos é de 245 alunos, distribuídos em duas turmas do curso Técnico em Administração ( $\mathrm{A}$ e $B)$, quatro turmas do Curso Técnico em Agropecuária ( $A, B, C$ e E) e duas turmas do curso Técnico em Manutenção e Suporte em Informática (A e B), totalizando oito turmas.

Como instrumento de coleta de dados foi elaborado um questionário composto por 35 questões (fechadas e abertas) para ser respondido pelos estudantes, por escrito e de forma voluntária. Inicialmente o instrumento apresentou um campo para identificação do estudante, de preenchimento opcional, seguido de informações sobre o sexo, a idade, o local de moradia e o curso técnico. $\mathrm{Na}$ sequência as perguntas indagavam sobre escolhas, dificuldades e percepções dos adolescentes sobre o contexto escolar e possíveis reflexos no seu bem-estar e saúde mental. $O$ instrumento assim como o projeto de pesquisa foi submetido e aprovado pelo Comitê de Ética em Pesquisa com Seres Humanos do Instituto Federal Farroupilha sob o número de registro Caae 08918419.3.0000.5574 e foi realizada mediante a assinatura dos Termos de Consentimento Livre e Esclarecido (TCLE) e dos Termos de Assentimento (TA), para a autorização dos pais dos estudantes menores de 18 anos.

Respondidos os questionários passou-se ao desenvolvimento do método eleito para a análise dos dados, a saber, análise de conteúdo, o qual Bardin é referência. Segundo o autor, análise de conteúdo consiste em

um conjunto de técnicas de análise das comunicações visando obter, por procedimentos, sistemáticos e objetivos de descrição do conteúdo das mensagens, indicadores (quantitativos ou não) que permitam a inferência de conhecimentos relativos às condições de produção/recepção (variáveis inferidas) destas mensagens. [...]. Esta abordagem tem por finalidade efectuar deduções lógicas e 
justificadas, referentes à origem das mensagens tomadas em consideração (o emissor e o seu contexto, ou, eventualmente, os efeitos dessas mensagens). (BARDIN, 1977, p. 42).

O autor supracitado orienta que as fases da análise devem ser organizadas em "três pólos cronológicos" (p. 95): o primeiro, pré-análise; o segundo, exploração do material; e por último, o tratamento dos resultados, a inferência e a interpretação.

A pré-análise geralmente compreende, segundo Bardin (1977, p. 95), "a escolha dos documentos a serem submetidos à análise, a formulação das hipóteses e dos objectivos e a elaboração de indicadores que fundamentem a interpretação final". Seguindo a descrição do autor, na primeira fase da análise, foi realizada a conferência dos termos de consentimento e de assentimento, adotando-se o seguinte critério de elegibilidade: dos questionários respondidos por alunos menores de 18 anos somente aqueles autorizados pelos responsáveis, por meio do Termo de Consentimento Livre e Esclarecido e do Termo de Assentimento, foram selecionados; dos questionários respondidos pelos alunos maiores de 18 anos, apenas foram selecionados aqueles em que o TCLE foi assinado pelo participante. Desta forma foi definido o corpus, definido por Bardin (1977, p. 96) como "o conjunto dos documentos tidos em conta para serem submetidos aos procedimentos analíticos", totalizando 87 questionários. Partiu-se então para a preparação do material.

A fim de preservar a identidade dos participantes foram criados códigos para identificar cada questionário. Cada código foi composto por letras, que identificam os cursos, e por números, que identificam os respondentes. Os questionários do curso Técnico em Administração receberam as letras "AD", do curso Técnico em Agropecuária, as letras "AG" e do curso Técnico em Manutenção e Suporte em Informática, a letra "I". Desta forma, acrescidos da numeração sequencial, formaram-se os códigos, por exemplo: AD1, AD2, AD3, AG1, AG2, AG3, I1, I2, I3.

Após a identificação dos 87 questionários foi realizada o que Bardin (1977, p. 96) denomina "leitura flutuante", que é a primeira leitura do material de análise. Logo foi realizada a organização dos dados, na qual todas as perguntas e respostas foram transcritas dos questionários para uma planilha do programa Excelß. Cada uma das 35 questões ocupou, na mesma ordem do questionário, uma célula da primeira linha da planilha e cada identificação de questionário ocupou uma célula da primeira coluna da planilha.

A partir da organização dos dados procedeu-se a segunda e terceira etapa de análise: a exploração do material e o tratamento dos resultados e interpretação. A partir da disposição dos dados foram aplicados filtros nas respostas das questões objetivas e realizadas algumas quantificações consideradas relevantes. Segundo Bardin (1977, p. 115), "a análise qualitativa não rejeita toda e qualquer forma de quantificação". A partir destas análises foram criados gráficos que auxiliaram na visualização dos resultados.

Posteriormente foi realizada a análise de conteúdo das questões abertas e a partir da apropriação desta análise resultaram duas categorias que serão discutidas na análise dos resultados: "O contexto escolar nos processos de 
adoecimento" e "Os processos interativos no enfrentamento do sofrimento/adoecimento estudantil".

\section{RESULTADOS E DISCUSSÕES}

A análise dos dados resultantes desta pesquisa inicia-se pela caracterização dos sujeitos participantes, a partir das respostas às primeiras questões do instrumento de coleta de dados. Conforme descrito na metodologia, a coleta dos dados resultou em 87 questionários aptos para análise. Portanto, a amostra constitui-se de 87 estudantes do terceiro ano do ensino médio integrado da EPT nos cursos Técnicos em Administração (33\%), em Agropecuária (45\%) e em Manutenção e Suporte em Informática (22\%) do IFFar - Campus São Vicente do Sul.

A grande maioria, 84 estudantes, têm de 16 a 19 anos, portanto, de acordo com a faixa etária estabelecida pela OMS (10 a 19 anos), adolescentes. Do total de participantes, as meninas representam $51 \%$ e os meninos $49 \%$. Sobre a moradia, verificou-se que $47 \%$ dos estudantes moram com os pais e dos $53 \%$ de estudantes que moram em outros locais, $28 \%$ residem na moradia estudantil do IF.

Utilizando-se da metodologia indicada, conforme descrito anteriormente, apresentam-se as categorias resultantes da análise. A primeira categoria denominada "O contexto escolar nos processos de adoecimento" e a segunda, "Os processos interativos no enfrentamento do sofrimento/adoecimento estudantil". Desta forma, serão tecidas as discussões pertinentes em cada categoria a seguir. Em cada categoria apresentam-se alguns dados obtidos, permeados por fragmentos de respostas dos estudantes. Estes fragmentos, devidamente identificados, foram reproduzidos conforme manuscritos dos participantes.

\subsection{O CONTEXTO ESCOLAR NOS PROCESSOS DE ADOECIMENTO}

Esta categoria retrata a relação estabelecida entre o contexto escolar e situações de sofrimento/adoecimento mental na percepção dos estudantes, apresentando aspectos da instituição escolar que podem se constituir em elementos que interferem na saúde mental dos estudantes. À medida que a análise foi se desenvolvendo, foram encontrados registros que dão sustentação a esta categoria e serão descritos a seguir.

Analisadas as respostas ao instrumento de pesquisa foi possível verificar que, na percepção dos estudantes, experiências da vida escolar podem lhes causar sofrimento ou prejuízos ao bem-estar físico/emocional. Isso pode ser evidenciado em vários momentos da análise, inclusive quando $83 \%$ dos participantes responderam afirmativamente à questão 31 - Você acredita que experiências da vida escolar são capazes de causar sofrimento ou algum prejuízo ao bem-estar físico/emocional dos alunos? Esclarecendo a sua resposta afirmativa a questão, disse uma das participantes (AD27), se referindo 
aos prejuízos: "Emocional, quando o aluno se cobra muito, ele passa a se privar da vida social, sem sair com os amigos, família. Físico também engloba, porque quando se faz muitas coisas, não dormimos direito, por exemplo, menos de 8h, afeta muito"'.

A fim de verificar se haveria a mesma compreensão dos participantes quando está explícito o termo saúde mental, foi elaborada a questão 33 - Você acredita que questões relacionadas ao contexto escolar podem prejudicar a saúde mental dos estudantes? - - Significativos $74 \%$ dos participantes responderam afirmativamente à questão. Alguns alunos, quando foram responder ao questionário, chegaram a perguntar "as questões 31 e 33 não são a mesma coisa". Com isso, demonstra-se que a maioria dos participantes têm a compreensão de que sofrimento e/ou prejuízos ao bem-estar, físico ou mental, são prejuízos a saúde mental. Esses dados reforçam o lugar que a escola ocupa frente ao tema da saúde mental.

A relação entre contexto escolar e saúde mental foi sendo elucidada à medida que avançava a análise dos dados. Os estudantes não só acreditam que há relação entre situações do contexto escolar com a saúde mental, como registraram suas experiências, como quando responderam à questão 32 que indagava se algum deles apresenta ou apresentou alguma (s) dificuldade relacionada (s) ao contexto escolar que prejudica ou prejudicou o seu bemestar físico ou emocional ou tenha causado sofrimento.

Gráfico 1 - Respostas à questão 32

Apresentou algum sofrimento ou prejuizo ao bem-estar relacionado ao contexto escolar

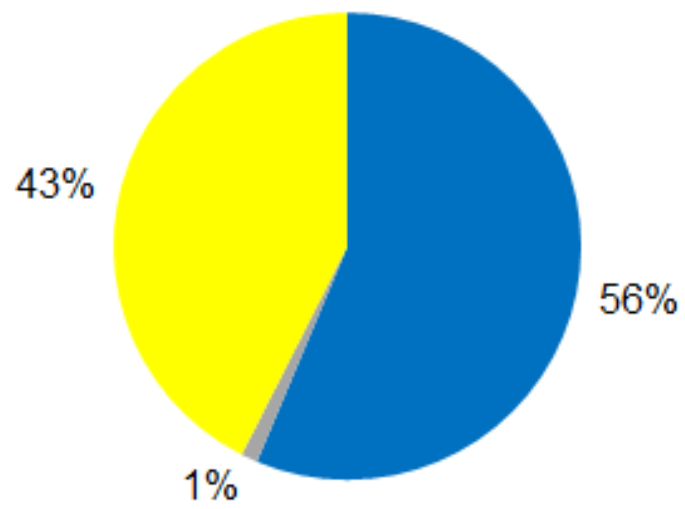

- Não

- Não respondeu

Sim

Fonte: Autoria Própria, 2019.

Observa-se no gráfico o representativo percentual de estudantes (43\%) que afirmaram apresentar ou ter apresentado prejuízos ao seu bem-estar físico ou mental ou algum sofrimento relacionado ao contexto escolar. Este dado permite inferir que os participantes reconhecem em suas experiências na instituição prejuízos a sua saúde mental. É válido salientar, estamos falando 
que 37 dos 87 estudantes participantes tiveram ou têm, a partir de dificuldades do contexto escolar, algum prejuízo a sua saúde mental. De acordo com Sousa, Araújo e Lima (2019, p. 169), os adolescentes, sujeitos desta pesquisa, assim como as crianças e jovens, constituem um "grupo etário vulnerável e de risco para os transtornos mentais". Desta forma a vigilância às questões de saúde mental de estudantes da EPT são pertinentes no sentido de evitar agravos.

Analisada a frequência dessas ocorrências de acordo com o sexo, podese verificar que os registros de prejuízos a saúde mental são mais frequentes nas meninas. Enquanto $33 \%$ dos meninos afirmaram apresentar ou ter apresentado dificuldades relacionadas ao contexto escolar que causaram sofrimento ou prejudicaram seu bem-estar físico ou emocional, $52 \%$ das meninas fizeram a mesma afirmação.

Gráfico 2 - Respostas à questão 32 de acordo com o sexo
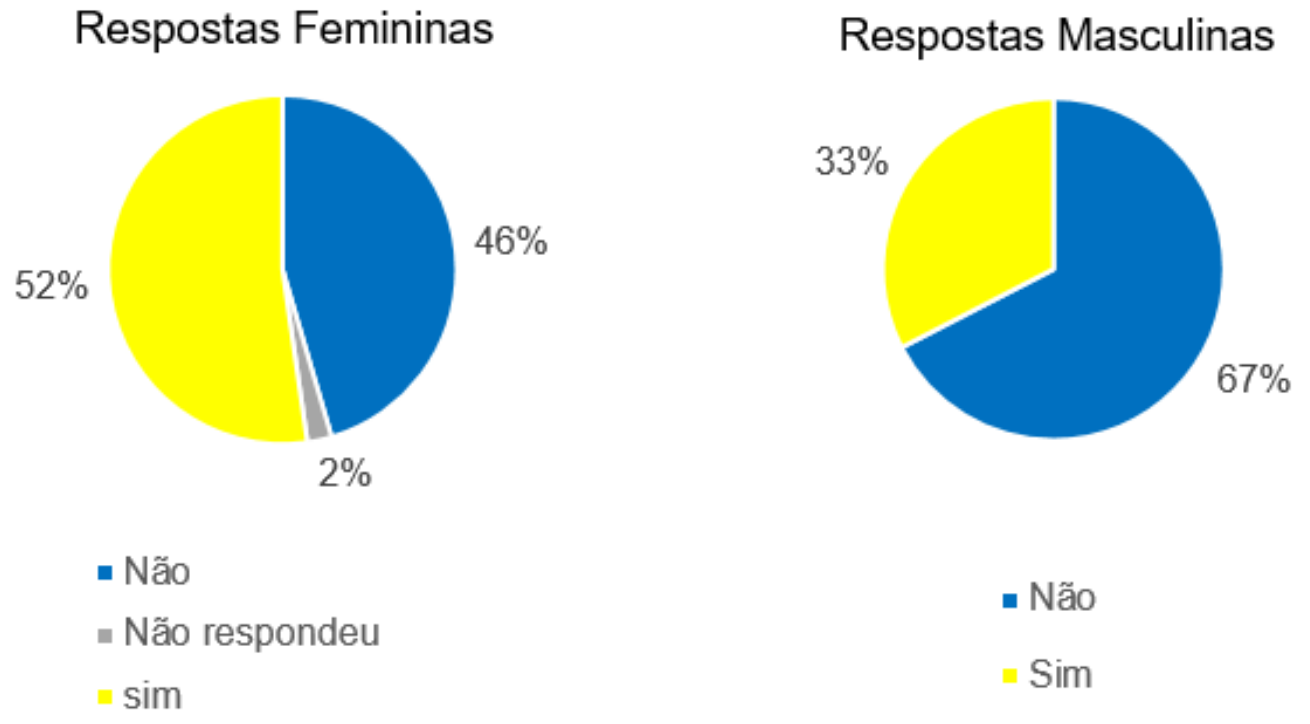

Fonte: Autoria Própria, 2019.

Ainda que o objetivo dessa pesquisa não tenha sido diagnosticar transtornos mentais, foi possível aproximá-la dos resultados da pesquisa de Lopes et al. (2016), que ao investigar a prevalência de transtornos mentais comuns $^{2}$ em adolescentes brasileiros identificou maior prevalência nas meninas quando comparadas aos meninos e seu ápice aos 17 anos, idade de grande parte dos estudantes participantes.

Jansen et al. (2011, p. 442) aponta uma possível justificativa para a maior prevalência de ansiedade e depressão nas mulheres, aferida por diversas pesquisas, que seria a sua "autopercepção de pior saúde do que os homens, sendo assim, expressam com maior facilidade seus sintomas e

2 Os transtornos mentais comuns (TMC) se caracterizam "principalmente pela presença de sintomas de depressão e ansiedade, além de diversas queixas inespecíficas e somáticas [...] quando presentes em crianças e adolescentes, podem ser manifestações iniciais e menos específicas de transtornos mentais mais graves, além de causarem prejuízo nas relações sociais e no aproveitamento escolar dessa população". (LOPES et al, 2016, p. 2s)

Vol. 1 (2020) 
procuram mais os serviços de saúde". A partir desta justificativa pode-se hipotetizar que, nesta pesquisa, as meninas possam ter revelado mais seus sofrimentos do que os meninos, reforçando pesquisas em que a prevalência de problemas de saúde mental é maior no sexo feminino.

Concluída a análise pontual da frequência dos registros em relação ao gênero, destacam-se os fragmentos de textos de alguns estudantes que relatam dificuldades, relacionadas ao contexto escolar, que Ihes causaram prejuízos ao bem-estar ou algum sofrimento. Revela um estudante: "Quando não conseguia aplicar algo que estudei me atacava dos nervos e chorava". Outro estudante, AD3 (18 anos), relatou que as dificuldades foram: "a $P P P^{3} e$ muitas vezes não ser bom o suficiente. $O$ medo junto com a pressão dos professores que acham que somos super heróis". Uma estudante de 17 anos desabafa "A quantidade de coisas para entregar me deixam ansiosa e quase louca" (AD10), sua fala foi reforçada por outro participante (AG20), que diz: "Já fiquei deprimido por notas baixas, por a rotina, por querer ficar em casa e não poder, por causa de provas ou compromissos maiores".

Nos textos citados aparecem duas unidades de registro muito significativas nesta relação entre contexto escolar e sofrimento/adoecimento, inclusive se repetiram em vários estudantes, a "ansiedade" e a "depressão". Foi possível verificar na análise que alguns estudantes revelam viver um sentimento ansioso e depressivo relacionados ao contexto escolar, constituindo-se como as principais formas de sofrimento e prejuízos ao bemestar dos estudantes participantes. Situações que podem se agravar e representar, como é o caso da depressão, fator de risco de suicídio (CFP, 2013). Ressalta-se que esta pesquisa não teve objetivo, em nenhum momento, de realizar diagnóstico, por isso esta é uma análise a partir da percepção dos estudantes, das suas experiências.

Nesta mesma perspectiva de análise, foi possível atingir o objetivo geral da pesquisa, o de investigar os possíveis fatores de sofrimento/adoecimento mental dos estudantes de cursos técnicos integrados ao ensino médio. Durante a análise dos dados fica evidente a impossibilidade de separar os fatores em emocionais, escolares, ou ainda relacionados a adolescência. Realizada a análise dos dados, foi possível verificar o quanto são interligados $e$ interdependentes os fatores identificados, por isso não será realizada nenhuma tentativa de classificá-los, mas sim identificá-los e propor ações de enfrentamento.

Conforme a percepção dos estudantes, foram identificados como possíveis fatores causadores de sofrimento ou prejuízos ao bem-estar: dificuldades de adaptação à instituição, dificuldades de relacionamento, bullying e pressão por bom desempenho escolar. Considera-se que os fatores citados se constituem como grupos de fatores, que se desdobram em outros, como será possível verificar ao longo do texto. Os diferentes fatores identificados na pesquisa coadunam com a característica multifatorial do

\footnotetext{
${ }^{3}$ A Prática Profissional Integrada (PPI) trata-se de práticas que articulam conhecimentos entre disciplinas da área básica e da área técnica do ano letivo e devem resultar no desenvolvimento de produção e/ou produto (escrito, virtual e/ou físico) e de sua socialização entre os estudantes e todos os docentes do curso.
} 
adoecimento (ARIÑO; BARDAGI, 2018). Passaremos ao primeiro grupo de fatores, as dificuldades de adaptação à instituição.

Ao serem questionados se tiveram dificuldades de adaptação à instituição, 39\% dos participantes respondeu afirmativamente. A partir das justificativas para as respostas afirmativas foi gerada uma nuvem de palavras que expressa as respostas mais frequentes.

Figura 1 - Nuvem de palavras de justificativas para as dificuldades de adaptação à Instituição



Fonte: Autoria Própria, 2019.

É possível verificar que "longe", "casa" e "família" aparecem com maior destaque por serem as palavras mais frequentemente citadas pelos estudantes. Portanto, de acordo com a percepção dos estudantes, ficar longe de casa e da família foi a maior dificuldade relatada no que se refere a adaptação à instituição. Demanda também identificada em outras pesquisas. Lorenzoni (2019) identificou, na fala de seus entrevistados, entre as demandas mais recorrentes dos estudantes do ensino médio à Rede de Apoio ao Estudante a "saudade de casa" (p. 53).

Ainda se referindo à adaptação à instituição, aparecem "adaptação", "carga horária" e "trabalhos" mostrando que a adaptação à carga horária e à demanda de trabalhos, também se destacam como dificuldades de adaptação à instituição. Ariño e Bardagi $(2018$, p. 50) reforçam por meio dos resultados de seu estudo com estudantes universitários a hipótese de "que a sobrecarga de demandas acadêmicas, assim como a percepção do estudante sobre sua capacidade de lidar com tais demandas, podem se constituir como um fator de risco para o adoecimento". Nas palavras de um participante, referindo-se à quantidade de trabalhos e a organização de horários, "a vida social tornou-se 
zero" (I15). Desta forma o grupo de fatores "dificuldades de adaptação à instituição" se constitui conforme a origem dessas dificuldades na percepção dos estudantes em: distância da família e a excessiva carga horária e de trabalhos.

Particularmente a questão da sobrecarga horária e de trabalhos relacionase a uma característica própria do ensino médio integrado à educação profissional. Segundo Lorenzoni:

O tempo dedicado às aulas e aos estudos muda consideravelmente em função da organização curricular, que exige turno integral, sendo esta uma das questões que mais afeta os estudantes, pois esta rotina não fazia parte de seu contexto escolar anterior. (2019, p. 54).

O elevado número de componentes curriculares resultam em carga horária elevada e grande número de trabalhos extraclasse. Condição que pode ser agravada se não houver, de fato, integração curricular e trabalho articulado entre os componentes curriculares. Para ilustrar o tamanho das demandas que podem ser geradas, apresenta-se uma breve descrição da organização curricular dos três cursos integrados - Agropecuária, Administração e Manutenção e Suporte em Informática.

Cada um dos cursos tem seus componentes curriculares dispostos em três núcleos de formação: básico, politécnico e tecnológico. O curso Técnico em Agropecuária totaliza a maior carga horária dos três cursos, 3.400 horas $^{4}$ para as disciplinas, 180 horas para a realização de estágio supervisionado obrigatório e 20 horas de orientação de estágio (IFFar, 2008). O curso Técnico em Administração totaliza para disciplinas 3300 horas, 100 horas para a realização de estágio curricular supervisionado obrigatório, 20 horas para a realização da orientação de estágio curricular supervisionado obrigatório e 80 horas de atividade complementar de curso (IFFar, 2014). Finalmente, a carga horária total do Curso Técnico em Manutenção e Suporte em Informática Integrado é a menor, 3100 horas para as disciplinas e não prevê estágio ou carga horária de atividades complementares (IFFar, 2011), mas ainda assim, acima da carga horária obrigatória para quem cursa apenas o Ensino Médio. Desta forma, compreende-se a queixa de muitos estudantes que se sentem sobrecarregados e muitas vezes angustiados com as grandes demandas.

Indagados sobre as dificuldades de relacionamento, verifica-se que os participantes relataram mais frequentemente dificuldades de relacionamento com os colegas do que com os professores. Ainda que essas dificuldades tenham sido mais significativas no início do curso, 35\% no relacionamento com colegas e $21 \%$ no relacionamento com professores, verificou-se que mesmo ao final do curso ainda são vivenciadas dificuldades de relacionamento, como pode ser visualizado no gráfico. 
Gráfico 3 - Respostas às questões 9 e 10 sobre dificuldades de relacionamento


Fonte: Autoria Própria, 2019.

Uma provável motivação para as dificuldades de relacionamento com os colegas pode ser o bullying, sofrido por aproximadamente $43 \%$ dos estudantes que relataram dificuldades de relacionamento com colegas em algum momento de sua experiência escolar no Instituto. Para Poletto e Koller (2008, p. 412) o bullying pode "configurar um fator de risco" para o desenvolvimento humano. Segundo Gurpilhares (2014) é evidente que este tipo de violência pode impactar na saúde de quem sofre, inclusive na aprendizagem.

As questões de violência entre os alunos, especialmente o bullying, foram citadas em vários depoimentos quando questionados sobre experiências da vida escolar capazes de causar sofrimento ou algum prejuízo ao bem-estar físico/emocional. Diz o menino de 17 anos, "O bullying pode causar esse tipo de prejuízo ao emocional, principalmente" (I14). Uma menina (18 anos) considera que "O bullying seria a pior consequência pois deixa a pessoa com baixa estima e sempre se diminuindo para os outros" (AD8). A colega de 17 anos cita mais violências "Bullying, acontecimentos de falta de respeito, deboche por parte dos colegas, etc" (AD15). As consequências dessas violências ficam evidentes no depoimento do estudante que fala da humilhação como causa de sofrimento: "Quando você é humilhado por seus colegas a ponto de querer morrer" (AD6).

Desta forma, acredita-se que trabalhar as questões éticas com os estudantes pode ser um caminho para amenizar as dificuldades de relacionamento relatadas, inclusive as violências como o bullying. Segundo Fernando Savater (2004) a ética é uma reflexão que cada indivíduo faz sobre a sua liberdade. Partindo desse princípio, estas situações evidenciam que alguns estudantes não sabem lidar com as suas liberdades, de modo que quem agride invade a liberdade daquele que é agredido. Savater (2004, p. 113) diz que um dos princípios mais fundamentais da ética é "Não faças aos outros o que não queres que te façam". Parece básico, mas não está sendo colocado em prática quando as relações humanas estão sendo prejudicadas por práticas como 0 bullying. 
A pressão por desempenho foi citada em diferentes momentos no instrumento. Frequentemente associada às notas, de acordo com as percepções dos estudantes, a pressão por um bom desempenho também se constituiu como um possível fator de sofrimento/adoecimento para os estudantes. Analisando diversos estudos sobre saúde mental de estudantes universitários Graner e Cerqueira (2019) identificaram que alunos que se sentiam pouco pressionados apresentaram melhor saúde mental. Desta forma, - estudo supracitado reforça o potencial prejuízo a saúde mental dos estudantes quando se trata da pressão por desempenho. Esta pesquisa identificou que a cobrança pessoal e dos pais/familiares apresentaram-se como as mais frequentes. Dos 87 participantes, 52 afirmam que se cobram muito.

Diz a menina de 17 anos, reconhecendo a pressão pessoal por desempenho: "No meu caso a cobrança que tenho comigo sobre meu desempenho é muito alta e então isso me afeta muito" (AD12). O colega de 18 anos também contribui falando da pressão que os estudantes se impõem: "Pois alunos que estavam acostumados a tirar notas boas no fundamental, se deparam com as notas do IFF que geralmente são baixas no início, ficam tristes, perdem a vontade de ficar estudando aqui" (AG32). Outros tantos compartilharam suas percepções no mesmo sentido: "Muitos se cobram muito, o que causa desgaste físico e mental com o medo de não conseguir" (AG37); "Um deles é a cobrança muito grande, tanto de si mesmo, dos familiares, e com isso a pessoa fica se colocando para baixo e do nada sem sua auto estima" (I10). "Algo que me marca bastante é a pressão para ir bem em uma prova. Eu estudo bastante, mas na hora de realmente mostrar meus conhecimentos e não lembro de nada (AD26).

A pressão por desempenho escolar exercida pela família foi a segunda mais sofrida pelos estudantes. Citada também nas questões abertas, como motivo de sofrimento e prejuízos ao bem-estar, o que fica evidente em alguns depoimentos: "Pressão por parte dos pais é a causa que + afeta a saúde mental dos alunos" (AG23). Outro estudante cita: "A pressão familiar e da sociedade para que se consiga o sucesso escolar" (I16) como prejudiciais à saúde mental dos estudantes.

Identificadas as principais dificuldades dos estudantes observou-se que a maior parte delas já se constituíam em queixas frequentes no setor de Assistência ao Educando, conforme o registro de uma psicóloga que atuou no IFFar - Campus SVS "dificuldades de adaptação, problemas relacionados à convivência, à saudade de casa, constrangimentos relacionados às brincadeiras entre "bixos" e veteranos, eram as queixas predominantes" (WALLAU; LORENZONI; ORTIZ, 2017, p. 48)

Ao discutir esta categoria que aponta alguns aspectos relacionados ao contexto escolar e que podem se constituir em elementos presentes nos processos de adoecimento, foi possível responder a um dos objetivos específicos da pesquisa, avaliar a percepção dos estudantes sobre a relação entre contexto escolar e sofrimento/adoecimento. É nítido, pelos depoimentos e análises realizadas, que, na percepção dos estudantes, esse contexto, próprio da escola, é capaz de causar prejuízos ao bem-estar físico e/ou mental, sofrimento e adoecimento. Para Poletto e Koller (2008) qualquer contexto, inclusive a escola, podem apresentar fatores de risco ou proteção, dependendo 
da qualidade das relações que se estabelecem nesses ambientes. De acordo com Ferro e Antunes (2015, p. 79) a escola é "um campo de coexistência, pois nele se convergem questões sociais, identitárias e políticas, produção de saber, falência do sistema familiar, o que torna a escola um universo complexo, por vezes perpassado pela angústia".

As palavras de Savater (2005) apontam alguns indícios da falência do sistema familiar e, portanto, dos prejuízos que pode causar à educação escolar. O autor sinaliza que as funções educacionais não estão sendo cumpridas pela família, no que Ihe compete. Savater (2005, p. 61) diz, "agora que a família não desempenha plenamente seu papel socializador, a escola, além de não poder realizar sua tarefa específica como no passado, também começa a ser objeto de novas demandas, para as quais não está preparada".

Estas novas configurações sociais da família e da escola, fazem com que as instituições assumam novas tarefas, como destacado por Savater no parágrafo anterior, tornando complexa a classificação do que compete a cada uma delas. Porém, o que se faz necessário é uma aproximação entre a família e a escola, principalmente no que tange a temática do adoecimento/sofrimento mental dos estudantes.

Desta forma, destacamos que os fatores identificados não são exclusivos do contexto escolar, nem ocorrem de forma isolada, a "interação de uma pessoa em determinado lugar, por exemplo, na escola, é influenciada pelo ambiente e também pelas influências trazidas de outros contextos, como a família" (POLETTO; KOLLER, 2008, p. 406). Mas os sujeitos que integram os diferentes setores e espaços da escola, em suas práticas e atividades, tem 0 compromisso profissional de conhecê-los e buscar formas de minimizar seus efeitos nos estudantes.

\subsection{OS PROCESSOS INTERATIVOS NO ENFRENTAMENTO DO SOFRIMENTO/ADOECIMENTO ESTUDANTIL}

A pesquisa apresentou a relação estabelecida entre o contexto escolar e a saúde mental na percepção dos participantes. Assim como, identificou aspectos da instituição escolar e características próprias do EMI capazes de interferir na saúde mental dos estudantes, por exemplo, a carga horária exaustiva e o excesso de trabalhos, consequências do grande número de componentes curriculares dos cursos integrados. Posteriormente a análise das dificuldades relacionadas ao contexto escolar relatadas pelos estudantes, passou-se a investigar como eles enfrentam essas dificuldades e de que forma a instituição e seus profissionais atuam frente às situações de sofrimento/adoecimento, visando minimizá-las. A partir dessas análises e reflexões constitui-se esta categoria.

Com a finalidade de conhecer sobre como os estudantes lidam com as questões relacionadas ao contexto escolar, buscou-se identificar de onde, ou de quem, esses estudantes recebem apoio emocional. Segundo Poletto e Koller (2008, p. 412) "o apoio emocional refere-se à disponibilidade de uma pessoa com quem a criança ou adolescente possa discutir seus problemas, 
confiar sentimentos e aborrecimentos". Visando identificá-lo, uma das perguntas, questão 16, indagou: Você recebe apoio emocional de alguém para enfrentar os desafios escolares? Nesta questão eles poderiam escolher mais de uma opção, caso desejassem, já que poderiam receber apoio de mais de uma fonte. As respostas são apresentadas no gráfico a seguir.

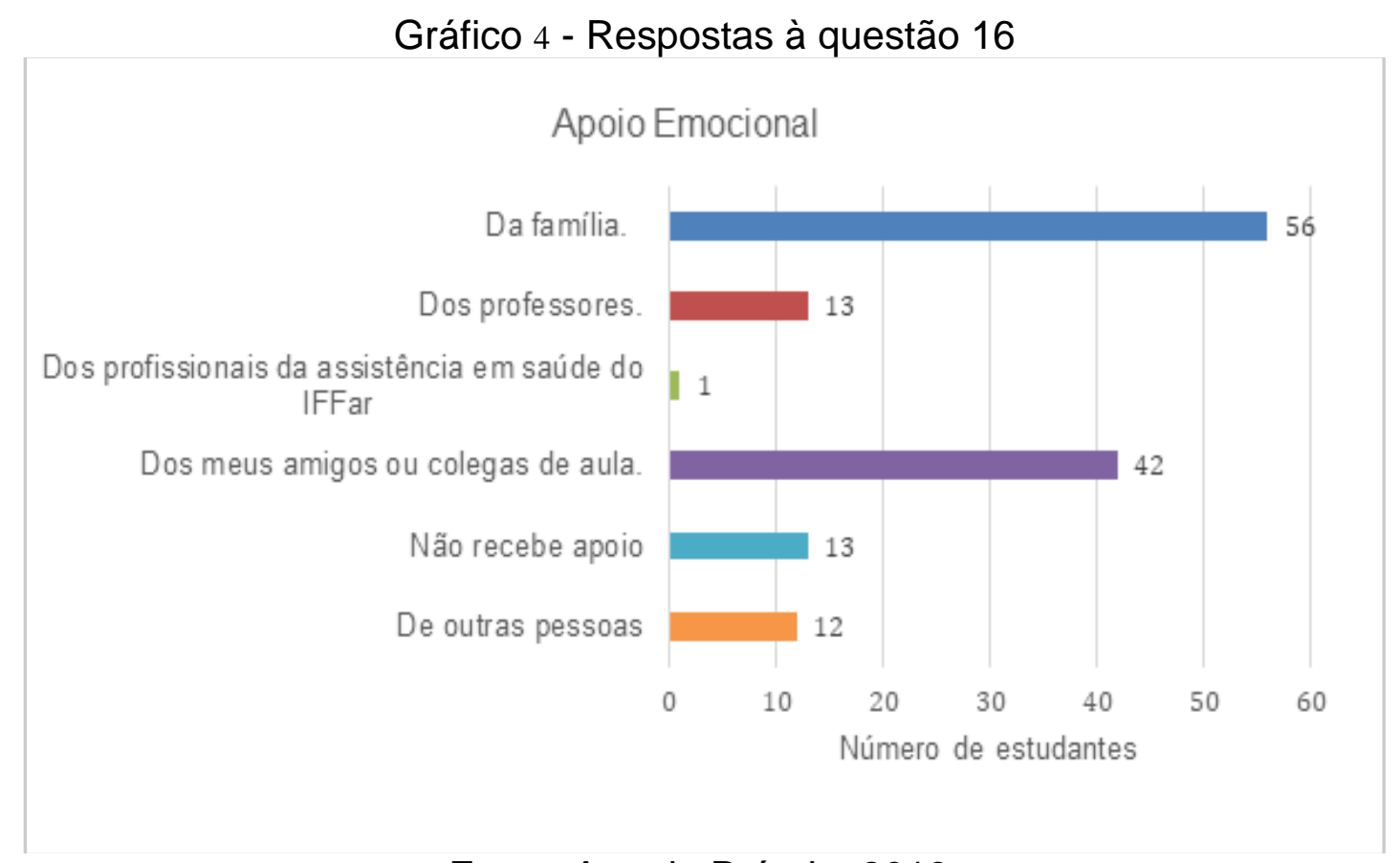

Fonte: Autoria Própria, 2019.

O apoio emocional recebido da família e dos amigos ou colegas de aula foram os mais citados. O mais representativo foi aquele recebido da família, citado por 56 dos 87 estudantes. Este pode ser um dos motivos pelos quais ficar longe da família foi uma das dificuldades mais relatadas, e segundo a percepção dos estudantes, se constitui um possível fator de sofrimento para estudantes que não moram com os pais, especialmente no início do curso, quando a saída de casa, na maioria deles pela primeira vez, é muito recente.

A estudante de 17 anos ao apontar quais as experiências da vida escolar acreditava serem capazes de causar sofrimento ou algum prejuízo ao bem-estar físico/emocional dos alunos, disse: "Muitos trabalhos, falta de tempo, ficar longe da família (não é o meu caso, mas vejo pelos meus colegas como é difícil "(AD13). Ainda que não seja a sua realidade, a estudante reconhece por meio da experiência dos colegas tal dificuldade. $O$ vínculo e a interação com a família representam, portanto, um amparo emocional importante para que os estudantes enfrentem as dificuldades escolares.

Segundo Souza, Baptista A. e Baptista M. (2010, p. 144), a família "[...] tem como função colaborar para o desenvolvimento de novos membros para a sociedade, socializando-os e outorgando-Ihes apoio físico e emocional". Desta forma para a maioria dos estudantes a família está cumprindo o seu papel, colaborando para a saúde psíquica, conferindo-lhes apoio emocional necessário. Os mesmos autores apontam que "a correlação entre o suporte familiar e saúde mental traduz a importância da família enquanto sistema 
protetor ou amenizador das situações de crise, o que colabora para a saúde mental de seus integrantes" (2010, p. 151).

No entanto observa-se que a proteção ou o risco estão atribuídos a qualidade das relações estabelecidas.

Em momentos de crise, a família pode ajudar o jovem a lidar com as situações problemas, atuando como sistema protetor. Por outro lado, o grupo familiar também pode operar como agente estressor, contribuindo para o desenvolvimento de doenças mentais em seus membros. (SOUZA; BAPTISTA A.; BAPTISTA M., 2010, p. 144).

Considerando o reconhecido apoio emocional familiar, frente à distância da família, muitos estudantes veem nos colegas uma fonte de apoio emocional. Por isso grande parte dos participantes, 42 deles, reconhecem receber apoio emocional dos amigos ou colegas de aula. Analisando em seu estudo a relação entre fatores acadêmicos e saúde mental de universitários Ariño e Bardagi apontam o referencial que diz "estabelecer bons vínculos com colegas é uma maneira de se ampliar e fortalecer a rede de apoio, o que pode auxiliar no enfrentamento dos problemas e melhora na qualidade de vida" (2018, p. 50).

Em diversos momentos dos questionários a interação com os colegas fica evidente como uma das formas de enfrentamento das dificuldades vividas no contexto escolar. Segundo Graner e Cerqueira (2019, p. 1341) "alunos que não dispõe de amigos para compartilhar momentos sociais, apresentam maior isolamento e sofrimento". Sobre estas relações estabelecidas com os colegas, durante a análise verificou-se, na sua maioria, que as dificuldades relatadas pelos estudantes eram maiores no início do curso e à medida que eles foram se conhecendo, interagindo e estabelecendo laços de amizade, as dificuldades foram amenizadas. Nestes casos, a experiência escolar torna-se mais agradável e segundo alguns dos relatos, amizades construídas no Instituto serão continuadas mesmo após o fim do curso. Diz o menino de 17 anos: "No começo tive certas dificuldades em me adaptar, principalmente porque não conhecia ninguém, mas logo isso mudou" (I14). O colega de curso revela o apoio recebido: "Tenho uma vivência muito boa pois desde o inicio fiz muitas amizades que sempre me apoiaram em tudo e mesmo com meus problemas consegui chegar no 3ํㅗ sem uma reprovação" (I7).

O apoio recebido parece ser fundamental para a superação das dificuldades encontradas pelos estudantes ao longo de suas experiências escolares, permeada por muitos desafios, compromissos e responsabilidades. Algumas dessas dificuldades podem, inclusive, motivar a desistência do curso ou da instituição. Neste sentido, ao relatar os pontos negativos das vivências no IFFar, diz a estudante: "No começo os pontos negativos era a minha adaptação com a rotina do IFFar, e também a saudade de casa, o que me fazia querer desistir' (AD27). Apesar de 98\% dos estudantes se considerarem satisfeitos com a sua experiência escolar no EMI, $63 \%$ pensa ou pensou em desistir do curso em algum momento, 48\% deles apenas no início do curso, conforme demonstra o gráfico. 
Gráfico 5 - Respostas à questão 19

Você já pensou em abandonar o curso?

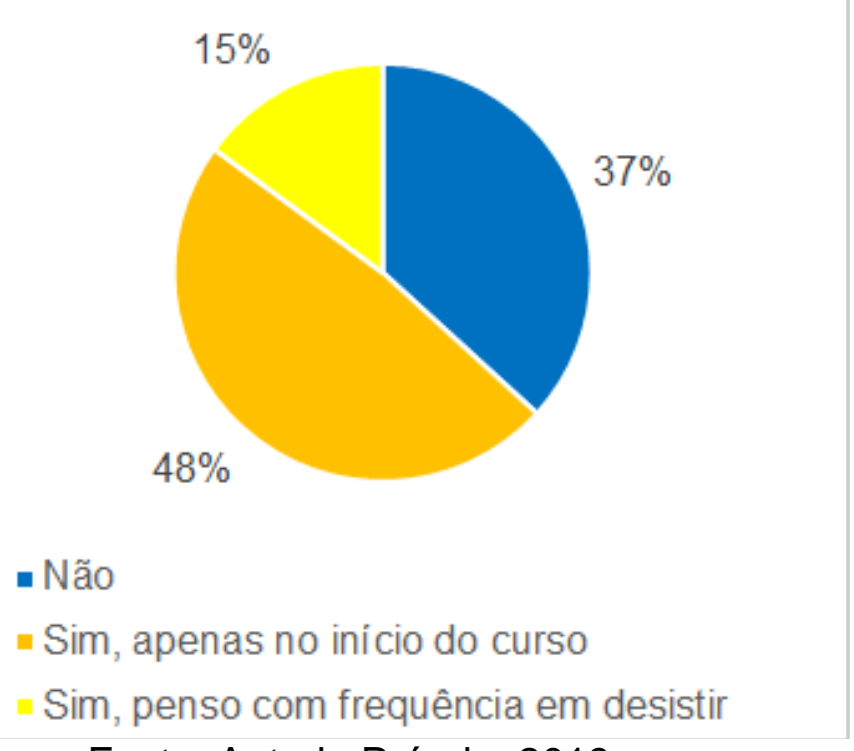

Fonte: Autoria Própria, 2019.

Lorenzoni (2019) destaca em sua pesquisa no mesmo campus a preocupação da instituição com as situações de abandono dos alunos.

\begin{abstract}
$\mathrm{Na}$ instituição há uma preocupação, um cuidado com tais situações que se traduziu na criação do Programa Permanência e Éxito (PPE), que tem por objetivo desenvolver uma cultura institucional sobre 0 tema, bem como promover a formação dos servidores para atuarem de forma a enxergarem e acolherem esses estudantes. Dentre as ações previstas, está o acolhimento das turmas ingressantes por meio de reuniões e atendimentos individuais aos estudantes. (LORENZONI, 2019, p. 53).
\end{abstract}

Verificou-se, de acordo com os depoimentos, que as interações entre os colegas parecem ter um papel importante para que o número de estudantes que pensa em abandonar o curso seja reduzido com o tempo. Se, por um lado, as dificuldades de relacionamento com os colegas podem constituir-se como motivo de sofrimento, como a prática do bullying, e, portanto, prejudiciais à saúde mental; por outro, quando as interações entre os colegas são bemsucedidas, uns apoiam os outros e isto serve de incentivo a permanecer na instituição e também uma forma de amenizar a saudade da família.

Prosseguindo com a análise, observou-se que outras pessoas foram reconhecidas como fonte de apoio emocional para os estudantes. Quando solicitados a identificar essas pessoas, os namorados lideraram, seguidos dos amigos que não estudam na instituição. O esporte também foi reconhecido como fonte de apoio emocional. Diz um menino, AG16, que recebe apoio emocional jogando e reforça quando se refere aos pontos positivos da experiência na instituição: "os jogos e as viagens da escola". Outros relatos também evidenciam o esporte como fonte de apoio. Falando sobre a sua experiência, disse o estudante: "Acredito que foi muito marcante, porque além 
de fazer muitos amigos, eu fazia parte da equipe esportiva do campus, que me agregou muito fisicamente e mentalmente" (AD28). Acredita-se que parte deste apoio relacionado ao esporte, esteja centrado na convivência com estudantes de outras turmas e outros cursos nas equipes esportivas, ampliando a rede de interações, fazendo novas amizades.

Nesta busca por conhecer as fontes de apoio emocional reconhecidos pelos participantes, destacou-se que apenas 1 estudante tenha citado receber apoio emocional dos profissionais da assistência em saúde do IFFar. A partir desta informação, procurou-se aprofundar a análise neste ponto, na relação institucional. Neste sentido, buscou-se identificar se os estudantes reconhecem espaços disponíveis para discutir sobre a saúde mental no contexto escolar. $O$ gráfico a seguir nos mostra um panorama.

\section{Gráfico 6 - Respostas à questão 34}

\section{Existe algum espaço para discutir sobre a saúde mental no contexto escolar?}
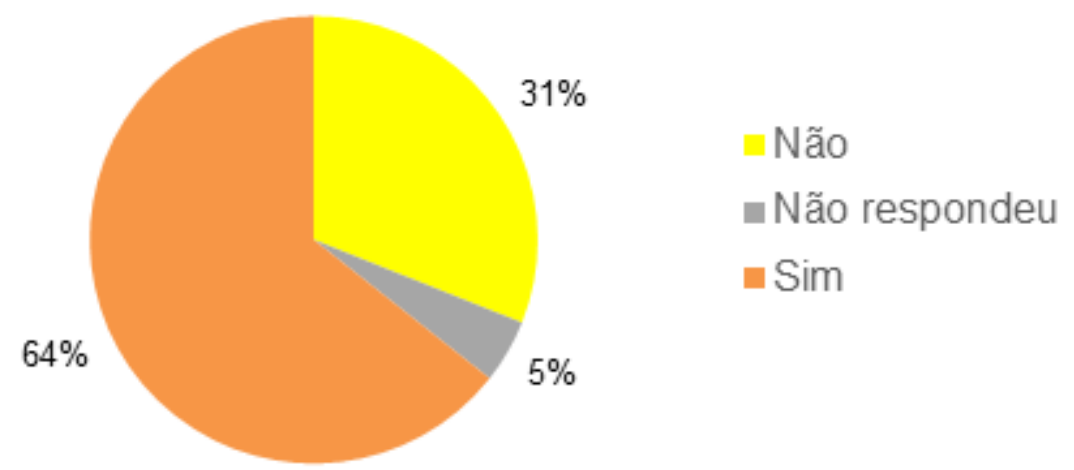

Fonte: Autoria Própria, 2019.

Conforme pode-se verificar no gráfico, $64 \%$ dos estudantes responderam afirmativamente à questão e, portanto, reconhecem que existem esses espaços de discussão. A partir das respostas discursivas, que identificaram quais seriam esses espaços, foi criada uma nuvem de palavras que apresenta em destaque aquelas citadas com maior frequência. A seguir pode-se visualizar a nuvem. 
Figura 2 - Nuvem de palavras dos espaços de discussão existentes

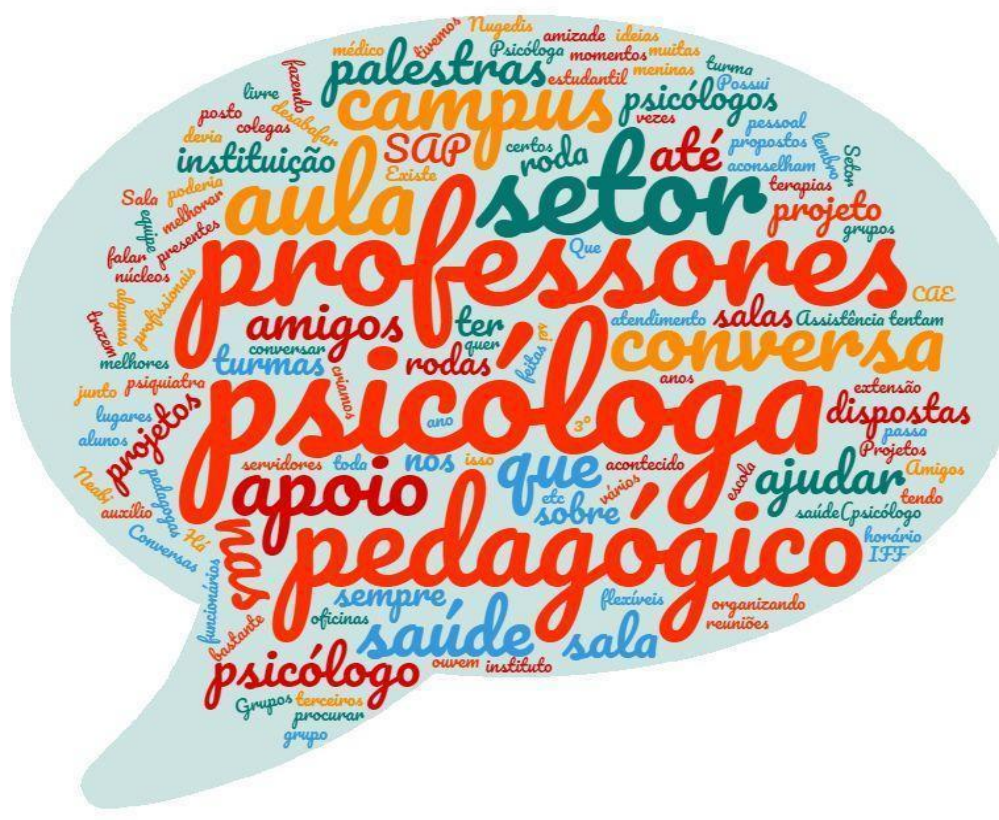

Fonte: Autoria Própria, 2019.

Observa-se que a palavra "psicóloga", exibida no centro, com maior destaque, foi a mais citada e também se referem a este profissional, as derivações de número e gênero: "psicólogas" e "psicólogo", representados em menor tamanho. Depoimentos dos alunos identificaram atuações atribuídas a este profissional. A mesma estudante, AD27, que anteriormente revelou a sua vontade de desistir da instituição devido as suas dificuldades, destacou nos pontos positivos de sua experiência no Instituto o atendimento psicológico. Ela disse: "(...) o IFFar colaborou muito para minha permanência, como conversas com a psicóloga". Ainda que a experiência tenha sido sofrida e as dificuldades Ihe fizessem querer desistir, a estudante encontrou na instituição, especialmente nas conversas com a psicóloga, o apoio necessário para permanecer.

Ainda tecendo sobre a atuação deste profissional, estudantes destacam as atividades realizadas pela profissional em exercício durante o terceiro ano dos cursos: "a psicóloga está organizando oficinas de conversa" (I19); "projeto da psicóloga que passa nas turmas de $3^{\circ}$ ano" (AD2); "está tendo algumas reuniões e projetos de conversa com a psicóloga e isso é muito bom para quem quer melhorar ou desabafar, devia ter mais palestras" (AG20). Os depoimentos dos estudantes descrevem como salutares essas ações e reafirmam os processos de interação com a profissional como espaços ou momentos para falar de saúde mental. Dessas informações depreende-se a identificação do profissional de psicologia quando se trata de saúde mental no contexto escolar.

Nota-se que em poucos momentos a assistência em saúde foi citada pelos estudantes. Parece ser frágil a relação estabelecida entre o setor e os estudantes, pois eles não o identificam como um espaço em que possam 
discutir sobre a saúde mental. Estão centradas na psicóloga as demandas relacionadas a saúde mental e esta profissional não é reconhecida como integrante do setor de assistência em saúde. Este parece ser o motivo pelo qual apenas um estudante disse receber apoio emocional dos profissionais da assistência em saúde do IFFar. A aparente limitação do reconhecimento dos demais profissionais, concentrando-se as questões de saúde mental na psicóloga, pode reduzir a atuação da assistência em saúde no enfrentamento das situações de sofrimento/adoecimento vividas pelos estudantes.

Ainda que com menor frequência, a mesma nuvem de palavras, que destacou a presença do profissional da psicologia, destacou o setor "pedagógico" e os "professores" como locais ou pessoas com quem os estudantes podem discutir sobre a saúde mental no contexto escolar. Os estudantes reconhecem a atuação do Setor de Assistência Pedagógica (SAP) junto a psicóloga, especialmente pelo trabalho em conjunto que vêm fazendo nas turmas de terceiros anos durante 2019. Esta é uma ação, desenvolvida pelo SAP e a psicóloga, que reforça a importância do enfrentamento de situações de sofrimento/adoecimento dos estudantes por meio dos espaços/momentos de interação e escuta, e por isso constituem as reflexões desta categoria.

Neste mesmo sentido, alguns alunos destacaram a importância dos professores no processo de escuta. Além da psicóloga, "os professores ouvem bastante os alunos", disse o participante AG15; outro contribui reconhecendo os professores, além de outros, para discutir sobre saúde mental: "setor pedagógico; psicóloga; CAE; professores" (112). Depoimentos como estes indicam a importância da escuta para os estudantes. Tassinari (2003, apud FERRO; ANTUNES, 2015, p. 76) reforça o potencial da escuta quando diz que "atender o sujeito na sua necessidade de escuta é uma forma preventiva e promotora de saúde destinada a ele".

Retornando aos estudantes que não responderam à questão - "Existe algum espaço para discutir sobre a saúde mental no contexto escolar? " - ou responderam negativamente, verificou-se que um considerável percentual dos participantes, $36 \%$, não identifica, na instituição, algum espaço para que seja discutida a saúde mental neste contexto. Esse dado indica certa carência de espaços para tratar de um tema dessa relevância para a educação, como é a saúde mental dos estudantes. Solicitou-se, então, que os estudantes sugerissem os espaços desejados. A fim de visualizá-los foi gerada a nuvem de palavras a seguir. 
Figura 3 - Nuvem de palavras das sugestões de espaços de discussão



Fonte: Autoria Própria, 2019.

A palavra "conversa" é central e aparece com destaque nas sugestões apresentadas pelos estudantes. Os momentos de interação, como os grupos e as rodas de conversas, foram os mais citados. Sugerem os estudantes: "poderia haver um espaço na aula de todos os professores" (AD3); "momentos de conversa com os alunos na sala de aula a cada mês, principalmente nos do $3^{\circ}$ ano que temos ENEM" (AD15); "reuniões em tempos livres para discutir sobre, e como melhorar algo que afeta tanto" (AD27). Apesar de alguns estudantes terem destacado a participação dos professores para discutir sobre saúde mental, observou-se nas sugestões que, para alguns, a inserção dos professores frente ao tema poderia ser maior: "rodas de conversa, confraternizações para discutir o assunto e participação mais ativa dos professores nesta questão" (AD1).

Ainda sobre a mesma questão, disse a menina: "eu não conheço nenhum lugar para isso mas seria bom ter algum para falar" (AD6). Apesar de reafirmar não haver espaços para discutir saúde mental no contexto escolar, ao qual se referiu como "isso", reconhece a importância de tê-los.

Depreende-se de toda a análise a necessidade dos estudantes de falar sobre o tema. Os depoimentos apontam que os espaços para discutir sobre as questões relacionadas a saúde mental no contexto escolar podem ser muitos, inclusive a sala de aula. Para isso, é preciso que existam pessoas dispostas a escutá-los. A sugestão de um estudante sobre os temas que ele considera importantes para discutir sobre saúde mental no contexto escolar deixa evidente a necessidade de escuta. $\mathrm{O}$ estudante de 17 anos, que revelou ter 
problemas de ansiedade, sugeriu os temas em formas de perguntas que ele gostaria que fizessem aos estudantes: Como anda a saúde mental de cada um? Estamos realmente bem? O que poderia fazer para ajudar-nos? Qual apoio precisamos? (I13).

Desta forma, a análise que permitiu constituir esta categoria aponta a importância dos processos interativos e da escuta no enfrentamento das dificuldades relacionadas ao contexto escolar e consequentemente no enfrentamento do sofrimento/adoecimento dos estudantes. As interações com os familiares, os colegas, amigos, professores, demonstraram-se ser fonte de apoio emocional e momentos de discussão sobre as questões de saúde mental.

Essas interações, que dão suporte aos estudantes no enfrentamento das suas dificuldades constituem o apoio social que é "visto como qualquer atividade que permita o compartilhamento de emoções e sentimentos com familiares, amigos ou grupos, e que ofereçam um apoio afetivo, emocional" (FONSECA; MOURA, 2008, p. s/n.). Um estudo demonstrou que pessoas com baixo apoio social têm 0 dobro de chances de apresentar TMC quando comparadas às que têm alto apoio social (COSTA; LUDERMIR, 2005), o que reforça a sua importância no enfrentamento dos prejuízos a saúde mental.

\begin{abstract}
Implementar ações que previnam o adoecimento mental perpassa diversos âmbitos da vida do indivíduo, incluindo sua saúde física, a qualidade dos seus relacionamentos, nível de satisfação e motivação com o trabalho ou estudo, qualidade do sono, tempo dedicado ao descanso e lazer, prática de atividade física. Nesse aspecto, o ambiente escolar pode ser um grande aliado. (MUNIZ; TROVÃO, 2019, p. 153).
\end{abstract}

\title{
4 CONSIDERAÇÕES FINAIS
}

As pesquisas relacionadas à saúde mental dos estudantes, abundantes no ensino superior, requerem atenção especialmente à EPT, que, em algumas modalidades, apresenta semelhanças ao contexto universitário, por vezes apontado como adoecedor. Utilizando-se do questionário, elaborado pelos pesquisadores, como instrumento de coleta de dados junto aos estudantes, este estudo de caso é resultado de nossos esforços em contribuir neste sentido, ampliando as discussões sobre a saúde mental de estudantes, neste caso, do EMI.

A dificuldade de adaptação à Instituição, neste estudo, motivada pela distância da família e excessiva carga horária e de trabalhos, aponta a relação de características e atividades dos cursos técnicos integrados da EPT com situações de sofrimento ou adoecimento dos estudantes, o que exige da Instituição ações efetivas de enfrentamento. No entanto, não é possível afirmar que os possíveis fatores são exclusivamente escolares, mas interdependentes e interligados a fatores de outras naturezas, pessoal, familiar,socioeconômicos, entre outros. Por isso, incentivamos a ampliação das pesquisas em vários 
aspectos relacionados ao tema, para que, a partir de novos conhecimentos seja possível desenvolver formas de enfrentamento das problemáticas relacionadas à saúde mental dos estudantes de forma mais efetiva.

A identificação, por parte dos estudantes, da importância dos processos de interação com colegas, professores e servidores como formas de enfrentamento das dificuldades relacionadas ao contexto escolar., foi fundamental para que se possam construir alternativas para diminuir a problemática em questão. Por outro lado, identificamos que esses espaços de interação são insuficientes, especialmente os espaços de escuta, assim como as discussões e reflexões em relação à saúde mental dos estudantes ainda estão aquém do que poderia a Instituição e cada um dos servidores.

Encerramos essa pesquisa cientes de que há muitos aspectos relacionados à temática para serem analisados em futuras pesquisas. Temos consciência de que ela representa uma pequena contribuição para o IFFar, uma iniciativa de reflexão sobre a saúde mental dos estudantes a nível micro, já que a pesquisa foi desenvolvida no Campus de São Vicente do Sul, mas que propõe caminhos possíveis para todos os campi, permitindo que o processo de reflexão se estabeleça a nível macro, na Instituição como um todo, inserindo estudantes e servidores no enfrentamento das dificuldades relacionadas à saúde mental dos estudantes a partir da ampliação de espaços de discussão, de interação e de escuta.

\section{REFERÊNCIAS}

ARIÑO, Daniela Ornellas; BARDAGI, Marúcia Patta. Relação entre Fatores Acadêmicos e a Saúde Mental de Estudantes Universitários. Psicologia em Pesquisa, Juiz de Fora, v. 12, n. 3, p. 44-52, dez. 2018. Disponível em: http://pepsic.bvsalud.org/scielo.php?script=sci arttext\&pid=S198212472018000300005\&lng=pt\&nrm=iso. Acesso em: 02 out. 2019.

BARDIN, Laurence. Análise de conteúdo. Lisboa: Edições 70, 1977. 225 p.

BRASIL. Constituição (1988). Constituição da República Federativa do Brasil. Brasília: Senado Federal, Coordenação de Edições Técnicas, 2017. 522 p.

CONSELHO FEDERAL DE PSICOLOGIA. O Suicídio e os Desafios para a Psicologia. Conselho Federal de Psicologia. Brasília: CFP, 2013.

COSTA, Albanita Gomes da; LUDERMIR, Ana Bernarda. Transtornos mentais comuns e apoio social: estudo em comunidade rural da Zona da Mata de Pernambuco, Brasil. Caderno de Saúde Pública, Rio de Janeiro, v. 21, n. 1, p. 73-79, fev. 2005. Disponível em: http://www.scielo.br/scielo.php?script=sci arttext\&pid=S0102311X2005000100009\&lng=en\&nrm=iso. Acesso em: 02 out. 2019.

FERRO, Aline S.; ANTUNES, André A. Plantão psicológico: a construção de um "pro-jeto" sobre as vicissitudes humanas no espaço educacional, narrando a intertextualidade de uma experiência psicológica no Instituto Federal de 
Goiás. Revista EIXO, Brasília, v. 4, n. 1, jan./jun. 2015. Disponível em: http://revistaeixo.ifb.edu.br/index.php/RevistaEixo/article/view/213. Acesso em: 3 mar. 2019.

FLICK, Uwe. Introdução à pesquisa qualitativa. 3. ed. Porto Alegre: Artmed, 2009. $405 \mathrm{p}$.

FONSECA, Ilva Santana Santos; MOURA, Samara Bruno. Apoio social, saúde e trabalho: uma breve revisão. Psicologia para América Latina, México, n. 15, dez. 2008.2 Disponível em: http://pepsic.bvsalud.org/scielo.php?script=sci arttext\&pid=S1870350X2008000400012\&lng=pt\&nrm=iso. Acesso em: 02 out. 2019.

GRANER, Karen Mendes; CERQUEIRA, Ana Teresa de Abreu Ramos. Revisão integrativa: sofrimento psíquico em estudantes universitários e fatores associados. Ciência \& Saúde Coletiva, Rio de Janeiro, v. 24, n. 4, p. 13271346, abr. 2019.

Disponível

em:

http://www.scielo.br/scielo.php?script=sci arttext\&pid=S1413-

81232019000401327\&lng=en\&nrm=iso. Acesso em: 02 out. 2019.

GROLLI, Verônica; WAGNER, Marcia Fortes; DALBOSCO, Simone Nenê Portela. Sintomas Depressivos e de Ansiedade em Adolescentes do Ensino Médio. Revista de Psicologia da IMED, Passo Fundo, v. 9, n. 1, p. 87-103, nov. $2017 . \quad$ Disponível em: https://seer.imed.edu.br/index.php/revistapsico/article/view/2123. Acesso em: 31 out. 2018.

GURPILHARES, Marlene Silva Sardinha et al. Bullying na Escola: um sofrimento. Educação, Cultura e Comunicação, [S.I.], v. 5, n. 10, jun./dez. 2014. Disponível em: http://unifatea.com.br/seer3/index.php/ECCOM/article/view/532. Acesso em: 01 mai. 2019.

INSTITUTO FEDERAL FARROUPILHA. Projeto Pedagógico do Curso Técnico em Agropecuária Integrado - Campus São Vicente do Sul. São Vicente do Sul: IFFar, 2008.

INSTITUTO FEDERAL FARROUPILHA. Projeto Pedagógico do Curso Técnico em Manutenção e Suporte em Informática Integrado - Campus São Vicente do Sul. São Vicente do Sul: IFFar, 2011.

INSTITUTO FEDERAL FARROUPILHA. Projeto Pedagógico do Curso Técnico em Administração Integrado - Campus São Vicente do Sul. São Vicente do Sul: IFFar, 2014.

JANSEN, Karen et al. Transtornos mentais comuns e qualidade de vida em jovens: uma amostra populacional de Pelotas, Rio Grande do Sul, Brasil. Caderno de Saúde Pública, Rio de Janeiro, v. 27, n. 3, p. 440448, mar. $2011 . \quad$ Disponível em: http://www.scielo.br/scielo.php?script=sci arttext\&pid=S0102-

311X2011000300005\&lng=en\&nrm=iso. Acesso em: 02 out. 2019. 
LOPES, Claudia S. et al. ERICA: prevalência de transtornos mentais comuns em adolescentes brasileiros. Revista de Saúde Pública, São Paulo, v. 50, supl. 1, 14s, 2016.2 Disponível em: https://scielosp.org/pdf/rsp/2016.v50suppl1/14s/pt. Acesso em: 30 out. 2018.

LORENZONI, Janete Cordeiro. Rede de Apoio aos Estudantes: seu papel no processo de aprendizagem dos estudantes no Instituto Federal Farroupilha Campus São Vicente do Sul. 2019. 99 p. Dissertação (Mestrado em Ensino de Humanidades e Linguagens) - Universidade Franciscana - Santa Maria, 2019.

MUNIZ, Maiara Amorin; TROVÃO, Renata Cardozo. A implementação do Plano Institucional de Promoção da Saúde Mental e Prevenção do Suicídio do IFMA. In: NEGREIROS, Fauston; SOUZA, Marilene Proença Rebello de (Org.). Práticas em psicologia escolar: do ensino técnico ao superior. v. 10. Teresina: EDUFPI, 2019. p. 151-163. Disponível em: https://www.ufpi.br/arquivos download/arquivos/VOLUME 1020190903151406. pdf. Acesso em: 30 set. 2019.

Organização Mundial da Saúde (OMS). Saúde do adolescente. Disponível em: http://www.who.int/topics/adolescent health/es/. Acesso em: 01 out. 2018.

POLETTO, Michele; KOLLER, Sílvia Helena. Contextos ecológicos: promotores de resiliência, fatores de risco e de proteção. Estudos de Psicologia, Campinas, v. 25, n. 3, p. 405-416, set. 2008. Disponível em: http://www.scielo.br/scielo.php?script=sci arttext\&pid=S0103-

166X2008000300009\&lng=pt\&nrm=iso. Acesso em: 04 out. 2019.

SAVATER, Fernando. Ética para meu filho. 3. ed. São Paulo: Martins Fontes, 2004.

SAVATER, Fernando. O valor de educar. São Paulo: Planeta do Brasil, 2005.

SOUSA, Silvana Teixeira de Araújo; ARAÚJO, Ana Cláudia Lopes; LIMA, Juliana Reis. Saúde Mental e Qualidade de Vida na Escola: um projeto de extensão do IFPI Campus Teresina Zona Sul. In: NEGREIROS, Fauston; SOUZA, Marilene Proença Rebello de (Org.). Práticas em psicologia escolar: do ensino técnico ao superior. v. 10. Teresina: EDUFPI, 2019. p. 164-179. Disponível https://www.ufpi.br/arquivos download/arquivos/VOLUME 1020190903151406. pdf. Acesso em: 30 set. 2019.

SOUZA, Mayra Silva de; BAPTISTA, Adriana Said Daher; BAPTISTA, Makilim Nunes. Relação entre suporte familiar, saúde mental e comportamentos de risco em estudantes universitários. Acta Colombiana de Psicología, v. 13, n. 1, p. 143-154. 2010.2019 Disponível https://www.redalyc.org/articulo.oa?id=79815637013. Acesso em: 03 out. 2019.

WALLAU, Raquel de, LORENZONI, Janete Cordeiro, ORTIZ, Neiva. O Lugar da Psicologia no Instituto Federal Farroupilha Campus São Vicente do Sul e a Participação na Rede Interna de Atendimento/Acompanhamento de Estudantes. In: NEGREIROS, Fauston; SOUZA, Marilene Proença Rebello de 
(Org.). Práticas em psicologia escolar: do ensino técnico ao superior. v. 3. Teresina: EDUFPI, $2017 . \quad$ p. 42-57. Disponível em: http://libra.ifpi.edu.br/noticias/VOLUME03.pdf. Acesso em: 06 out. 2019.

YIN, R. K. Estudo de caso: planejamento e métodos. 5. ed. Porto Alegre: Bookman, 2015. 320 p. 